\title{
Professionalism, Scholarly Practice, and Professional Development in Student Affairs
}

\author{
Stan Carpenter \\ Matthew T. Stimpson
}

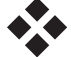

This article presents a synthesis of recent literature on professionalism in student affairs. Attention is given to the nature of professionalism, a discussion of student affairs as a profession, the scholarly practice of student affairs, and professional development in student affairs. The authors note that an assumption of professionalism pervades all activities in the field of student affairs, especially staffing and personnel matters. Implications are noted for individuals and organizations.
\end{abstract}

The purpose of this article is to synthesize recent thinking and writing around the concept of professionalism in student affairs as an area of study and practice. It is not meant to be a review of the literature per se, in that no attempt is made to be comprehensive. Rather, "meta-" themes and concepts are extracted from the literature by the authors, with attention to multiple perspectives, but without true attention to critics of the notions surrounding professionalism. For those ideas, readers will need to look elsewhere.

Stan Carpenter is the chair of professional counseling at Texas State University, San Marcos. Matthew T. Stimpson is a doctoral student at Virginia Polytechnic Institute and State University (Virginia Tech) in Blacksburg, VA. 


\section{Definition of "Professional"}

What is meant by the term "professional?" One speaks of a professional basketball player, meaning someone who earns money from the game. A "real professional," as an appellation for a mason or a carpenter, means someone who is good at what he or she does or who exhibits unusually strong attributes of responsibility or fairness. There are even references to "professional" criminals! Occupational sociologists use rather more precise language, indicating that a profession is a special kind of work. What is it that distinguishes a technically proficient person from a professional?

Brint (1993), discussing the work of Eliot Friedson, asserted that professions arose as a handful of "learned occupations" (p. 270) and other positions for the upper class. The concept was expanded in the mid19th to mid-20th centuries to include many middle class occupations, before declining in influence as the society and control structures became more complex and confining. Three schools of thought seem to dominate. The first attempted to identify the traits necessary to define a profession. Brint said that, while no consensus existed, by the mid-60s "many analysts concentrated on the combination of expertise, collective organization and collegial control, ethical standards, and work in a "public service"' (p. 260).

A second area of research examined the process of professionalization. "This second approach clearly treats professions not as an easily identifiable entity, but rather as a status to which any number of white-collar occupations may aspire by attempting to adopt the forms of professionalization pioneered by established professions. ..." (p. 260). Such a construction was characterized by Wilensky (1964) who identified five stages in the professionalization process: a group of people engage full-time in important work; professional associations emerge; the development of a formal, academic course of study and preparation; political maneuvering to establish turf and legal and other sanctions; and an enforceable code of ethics. The third school denied any utility in the concept of professions, preferring to study the societal use of the term to denote certain occupations. Veysey (1988, p. 17) even suggested that professions were "nothing more than a series of rather random occupations that have historically been called that in our culture." 
Brint (1993) points out conceptual problems with each of these views, preferring Friedson's (1986) notion that professions are creatures of labor market organization and result from efforts to assure a measure of autonomy of practice as well as a "labor market shelter" (Brint, p. 262). Power and privilege grow out of this market shelter and the key ingredient in creation of this status is advanced education provided by, and only by, higher education institutions. Brint summarizes his arguments by stating:

Friedson's conception of professions as a socially constructed connection between tasks, advanced training, and markets seems to ... avoid many of the problems associated with previous conceptions. It is unencumbered by the empirically dubious ideas of trait theorists about public service orientations, high ethical standards, and collegial control ... allowing the likelihood that ... these attributes may quite naturally develop out of the distinctive labor market situation of professions. It shows the end point toward which the modern process of professionalization inclines ... tending to reconceptualize the process models ... around a more limited set of fundamental linkages. It connects phenomenological accounts of cultural labeling with concrete processes of occupational organization. It is the most theoretically sophisticated generic definition of professions that currently exists. (p. 264)

This discussion has shown that there is controversy and doubt surrounding the entire concept of professions, but it is undeniable that sociologists are studying an important phenomenon. Pavalko (1971) offered eight profession-occupation continua upon which it is possible to situate any job or type of work. These continua are:

1. Specialized theory and intellectual technique required

2. Relevance to basic social values and processes

3. Nature of preparation in terms of amount and specialization of training and degree of symbolization and ideation required

4. Motivation for work meaning service to society as opposed to selfinterest

5. Autonomy of practice

6. Sense of commitment or strength of calling to the profession

7. Sense of professional community and culture

8. Strength of codes of ethics (p. 4) 
All occupations can be placed on these continua and the notion of profession, then, depends upon the placements and the social constructions of the placements, in the context of labor markets and, the place of higher education in preparation for the occupation. This idea occupies a sort of middle ground between the trait thinking and the process models. A profession, for example, should require a high degree of specialized knowledge and skill, be based primarily upon a service motivation, should concern a crucial societal task(s), and should require an extended preparation, among other things (Carpenter, 2003).

In light of these and other definitions and ideas, Carpenter (1991) suggested that the existence and designation of a profession requires that the members of a profession substantially share goals. Also necessary are the existence of a professional community that supports members and stakes out boundaries and sanctions and attention to socialization and regeneration, including a reasonable consensus on appropriate preparation and an organized conception of career-long learning.

\section{Is Student Affairs Work a Profession?}

The extent to which the above heading elicits a groan is a sign of its premise. The appellation "profession" is now routinely applied to the field of student affairs work, even though it may not apply when using a trait model, even a modified one such as Pavalko (1971) described. By 1980, Carpenter, Miller, and Winston established that student affairs work was an "emerging profession" (p. 21) based upon an analysis of sociological criteria suggested by Wilensky (1964) and despite a host of earlier literature to the contrary. After 21 years, Winston, Creamer, and Miller (2001), came to the same conclusion.

Indeed, revisiting the Pavalko (1971) continua (above) as applied to student affairs work, one can see that (a) there is disagreement about the level of theory and intellectual technique involved, not to mention that the theory base is not particularly specialized (Blimling, 2001; Evans \& Reason, 2001); (b) relevance to society could be arguable, since not everyone attends college and some institutions de-emphasize student affairs; (c) the nature of appropriate professional prepara- 
tion is contested (Janosik, Carpenter, \& Creamer, 2006); (d) service motivation versus self-interest is always difficult to establish in any occupation, although the service argument is perhaps buttressed by the low salaries paid to practitioners (NASPA, 2006); (e) autonomy of practice in student affairs is proscribed by considerations of institutional mission and by the fact that students must choose to take advantage of student affairs services and programs (Carpenter, 2003); (f) commitment and calling can be questioned due to the relatively high drop-out rate in the profession (Hirt \& Creamer, 1998); (g) our sense of professional culture seems high, but it is fragmented by our multiple associations and specialties (CAS, 2003); and (h) codes of ethics in student affairs abound, but enforcement mechanisms are weak (see the ACPA Statement of Ethical Principles as one example). So, at least from a trait perspective, student affairs work seems to be making little headway toward professional status. Closer analysis belies this conclusion. The nature of the Pavalko continua suggests room for Brint's (1993) process and social construction considerations. In other words, as long as a case can be made to put student affairs work toward the profession end of the continua, the fact that it does not strictly conform to traditional traits

. . may not matter in practice. Stamatakos (1981), among others, held that, profession or not, professional behavior was expected of student affairs practitioners on campus and by their peers. Indeed, much of the literature and most of the practices of student affairs in hiring, in professional development and associations, and in many other functions so closely mimic those of [other] professions as to be indistinguishable (Carpenter, 2003, p. 575).

If practitioners in the field act professionally, think professionally, and hold themselves out to be professionals then they will go a long way toward making their preferred social constructions "actual."

Something even more interesting may be occurring with the student affairs profession. Trait or process, reality or construction, the strictures of traditional professions do not fit this occupation very well. The core values of the field (Young, 2001) are not compatible with those of many professions, if one is to listen to the critics of inherent elitism and exclusivity (Brint, 1993). It may be that what seems like a poor fit from a trait standpoint is actually an evolutionary move to a 
new kind of profession, one that keeps the best of community and regeneration while eschewing more limited models of boundary setting such as licensure and preparation monopolies (Carpenter, 2003). Is student affairs a profession? For all practical purposes, yes.

\section{Student Affairs Practice and Scholarship}

If student affairs work is a profession, then it follows that there must be some basis to practice other than simply technical or service oriented. For brevity this can be called theory, implying a fruitful examination of theory into practice. A treatment of the nature of and the many and varied sources of what is called theory in student affairs is beyond this piece, but a lively literature that has arisen around the idea of the scholarly practitioner or, if one likes, the practitioner scholar.

To begin, it may be helpful to consider some summary pieces from some of the finest minds in the field. First, Nancy Evans with Robert Reason (2001) tackled the task of a thematic analysis of many of the statements of which our field is so fond, covering several decades, from the Student Personnel Point of View (1937) to the Trends project. They suggested that the blue ribbon groups assigned these tasks and consistently tended to write about our views of students, the importance of the environment to our work and students' success, the nature of our field and our practice/roles, and our responsibility to society. Not satisfied to demonstrate that there was very little new under the student affairs sun, they went on to call for a renewed sense of activism on campuses in service of the values of our profession.

In some sense confirming that many things have not changed as much as we might think in our field, Blimling (2001) wrote that most of the roles that we have historically played on campuses and in our divisions are still extant and can best be understood in terms of "communities of practice" (p. 387). That is, the student services approach, the student administration model, student development, and student learning all have scholarship, mores, and structure that attach and we must choose in which to be most adept in, but should be familiar with each, especially at the senior level. 
Turning to the NASPA Journal special issue on scholarship, Malaney (2002) discussed the lack of cooperation between preparation programs and practitioners in divisions. He says we need to expand the reach of our knowledge of scholarship and scholarly techniques. Our students are not even getting what they need, much less the student affairs divisions on our campuses. Assessment workshops are wildly popular precisely because we in the field are not doing our jobs. Malaney clearly calls for us to do better as a profession for all the right reasons.

But what does "do better" mean? Fried (2002) suggests that it will not look much like the past. That we need to recognize the things we already know and actualize the ways the world is coming to be understood in our work. We have to be more inclusive, pluralistic, open to change, and willing to think in different ways, using new paradigms for practice and for research and scholarship.

Allen (2002) issues a similar challenge, calling for recognition of interdependence, holism, and systems thinking. She also persuasively argues for renewed attention to the voices of practitioners in our professional literature. This is ironic, since many of the past criticisms of the field focused on the applied nature of much of our scholarship. But, as Fried (2002) pointed out, studies by Davis and Liddell (1997) and Saunders, Register, Cooper, Bates, and Dadonna (2000) show that practice and conceptual articles are losing out to research articles written largely by professors. Allen was calling for an addition of the practice voice as a balance and complement to the more traditional research.

The ACPA Senior Scholars published the report of the Trends Project in 1999, in the form of a series of brief framing papers built around questions in eight major areas of impact on education in the near and longer term. These eight trends were identified by doctoral students and faculty at the University of Maryland in 1997 through a content review of dozens of higher education reports and documents, a process led by Susan Komives. Questions and issues were posed in the following large categories: improving access and success for diverse students; affordability of higher education; learning and teaching in the 21st century; the impact of technology; the changing nature of work in higher education; collaboration and partnerships; account- 
ability, especially for student affairs; and changing government roles relative to higher education. It is easy to see echoes of our history as a field in this list-many of these issues have been around for a while. However, it is clear that some, such as technology and affordability, have reached a point of intensity that was unparalleled previously. This group of faculty and practitioners had in mind a profession-wide commitment to attacking these research agendas using the best of thinking and talents of each.

Despite such calls, there is a lack of systematic and detailed scholarship in the field that follows an agenda from start to wherever it leads, or better, several agendas. And if there were such scholarship available, would practitioners be able to read it, even if they had time to do so? Could they tell good from bad and translate it into policy and practice? Many would argue the answer is no. Schroeder and Pike (2001) tackled the question of reasons why practitioners might not be good at the scholarship of application and posited issues of institutional culture, the tyranny of the immediate, inadequate preparation, motivation and rewards, the tyranny of custom, fear of change, and lack of clear intentional purpose for practice. It may be that, since scholarship and research are frequently not familiar tasks, they are not considered to be as enjoyable or even as necessary as, say, advising a student organization president or planning a program, or any of the thousands of other tasks confronting busy student affairs workers.

Schroeder and Pike (2001), Saunders et al. (2000), and Fried (2002) all identified the separation of faculty from practitioners and the tendency of the former to perform research and scholarship in the absence of, and certainly without the collaboration of, the latter. Saunders et al. suggested that practitioners are doers, not thinkers. Malaney (2002) argues this as a failing of the faculty, the scholars. He thinks student affairs professionals should be reaching out more and more effectively.

The seeming separation of student affairs from academic affairs that has characterized at least the last four decades may be lessening with the renewed emphasis of the field on student learning. In any case, it seems to have led to something of an antipathy for things scholarly. After all, student affairs professionals are the "unfaculty," the haven, the refuge from all that "learning." Even if one does not subscribe to 
such thinking, it would be easy unintentionally to enable students to think that way. Given the difference in the two cultures and the endless supply of other ways to stay busy, many practitioners do not rely on research and scholarship to guide practice, much less do research themselves, other than the simplest kind of evaluation and what passes for assessment.

With this as backdrop, Carpenter (2001) used Boyer's broadened view of scholarship as a jumping off place to consider what scholarly practice of student affairs should look like. He argued that adopting the values of scholars would not only make faculty of all disciplines more at home with student affairs professionals, but would also lead to better practice. Scholarly practice was posited to be: intentional, theorybased, data-based, peer reviewed, tolerant of differing perspectives, unselfish, open to change, careful and skeptical, attentive to regeneration, and autonomous within institutional contexts. Boyer's scholarships of discovery, integration, application, and dissemination/teaching are thus used in the professional context and merged into what can be called a "scholarship of practice" (p. 317).

\section{Professional Development Writ Large}

Given that student affairs work constitutes an area of professional and scholarly practice, it follows that there exists a rigorous and continuous preparation process for a practitioner to be, and stay, fully qualified. Appropriate initial preparation is contested, as mentioned above, and a treatment of the extensive discussions around the topic is beyond this paper. Professional development, on the other hand, is universally valued, but perhaps with less understanding or commitment than would be ideal. Recent literature is extant concerning areas of competence that should be considered and the nature and process of continuous professional education.

Professional development has evolved over the past four and half decades and Cervero (2000) points to the "publication in 1962 of a conceptual scheme for the lifelong education of physicians" (p. 4) as the first indication that professional development was garnering attention. By the 1970s professional development was being used as a tool for relicensure, and during the 1980s professional development was 
being practiced in a variety of professions. Most had organized broad and detailed professional development programs (Cervero).

During the 1990s, professional development seemed to stall. This evolutional "pause" led Cervero (2000) to characterize professional development processes as being "devoted mainly to updating practitioners about the newest developments, which are transmitted in a didactic fashion and offered by a pluralistic group of providers (workplaces, for-profits, and universities) that do not work together in any coordinated fashion" (p. 4). The degree to which Cervero's characterization resonates with student affairs practitioner may vary from individual to individual, but it should at least sound familiar. Knox (2000) points to the divide between preparation programs and professional development programs as a major concern facing professional development activities, for example, implying a lack of theoretical focus.

If professional development programs are to flourish a "continuum of professional practice" (Knox, p. 16) must be adopted that views professional education as a lifelong process. Knox views the continuum being an organized, coordinated effort that focuses on "goals, learning activities, providers, resources, context, and negotiation" concerning the aspects of professional development (p. 17). The continuum of practice has other hallmarks as well. Professional development activities should pick up where professional preparation programs leave off and be responsive to needs. This entails both providing for individual needs and also being mindful of stereotypes in society that block professional growth (Knox). Professional development activities should be application focused. Encouraging professionals to apply what is learned is a natural and appropriate extension of professional development. Finally, professional development activities should receive support from all parties concerned with professional improvement, including administrators, learners, and policy makers (Knox).

Professional development can be defined in a variety of contexts and a variety of authors in the student affairs field have tackled the task. Winston and Creamer (1998) defined professional development as "an event or activity performed outside or beyond daily work duties and activities" (p. 29) and thought that it must be integrated with supervision for staff development to be the most effective. Woodard and Komives (1990) see professional development as allowing for contin- 
uous learning in order to ensure staff competence. Parallels have also been drawn between the training and professional development of student affairs workers with professionals in other fields like medicine, accounting, and law (Schwartz \& Bryan, 1998). More than likely, most professionals in student affairs would agree with these definitions and, indeed, Dirkx, Gilley, and Gilley (2004) view these descriptions of professional development as typical.

Dirkx et al. (2004) see the more traditional definition of "professional development" as being coupled tightly with mastery of skills and competencies. It is this traditional view of professional development that results in activities focused on new practices, techniques, and knowledge. Professional development activities are those in which practitioners engage in order to continually update their abilities. Knox (1993) had a similar view of professional development, seeing one purpose as furthering the knowledge of the professional. Using "systematic learning" (p. 275) the professional advances from a novice to an expert. That systematic learning that Knox speaks of is achieved through both formal (i.e., educational institutions) and nonformal (i.e., professional associations) educational experiences. An alternative view of professional development is contextual and subjective. This view focuses on relationships and how they impact learning, while also placing weight on the role that the individual plays in learning (Dirkx et al.).

In the more traditional role of professional development, the focus is on acquiring a particular set of skills (or new knowledge) that can then be applied in practice. However, the alternative view of professional development, as Dirkx et al. (2004) discussed it, concerns knowledge evolving as it is applied in the professional's practice by the professional. When knowledge, context of practice, and self are placed together, knowledge is not merely disseminated during a professional activity. Rather, knowledge gained from professional development activities is contextual and subjective.

Regardless of which author is defining professional development, the purpose is quite clear. Professional development is the career-long process of professional improvement. While the purpose of professional development is fairly straightforward, the traits professional development should be fostering can be more complicated. After all, 
the student affairs profession is vast and varied and the needs of one professional may not be the needs of another. Lovell and Kosten (2000) responded to a similar question by asking what are the necessary skills, knowledge, and traits for student affairs professionals and simplified the issue of what characteristics student affairs professionals should possess. Using a meta-analysis of research focusing on student affairs administrator skills, knowledge, and traits, Lovell and Kosten identified eight skills, six knowledge domains, and two personal traits that are identified in the literature as necessities for student affairs administrators.

Management issues were the most discussed skills in the research reviewed by Lovell and Kosten (2000). This should not come as surprise given the nature of student affairs work. Student affairs professionals are, after all, mostly administrators. Nor should it come as surprise that $78 \%$ of the studies reviewed by Lovell and Kosten focused on "human facilitation" (p. 561), like counseling and interpersonal skills. The prevalence of these skills is not news to student affairs administrator, but other skills identified by Lovell and Kosten are more recent and perhaps more surprising. They identified research, evaluation, and assessment, as well as enrollment management in their study. Assessment has become of particular importance recently and enrollment management is a term that would have been foreign to many 20 years ago. In the area of knowledge domains there are also items that have garnished increasing attention in recent years.

Knowledge of federal policies and regulations, an issue that many would say is more complicated today than in previous years was found to be present in the research reviewed (Lovell \& Kosten, 2000), as were knowledge of student development theory, knowledge of specific functional areas (i.e., residence life), and understanding of organizational behavior. The final area discussed by Lovell and Kosten was personal traits. These traits include the ability to work with others and personal integrity.

Lovell and Kosten (2000) provide a checklist of skills, knowledge, and traits necessary for success as administrators. None of them are surprises, as Lovell and Kosten note. In large measure, the characteristics reviewed reflect the goals of preparation programs and current professional development efforts and should be instrumental in enhancing 
individual performance and organizational performance, as discussed by Winston and Creamer (1997). On the one hand, professional development refines an individual's skill. On the other hand it serves the purpose of furthering the cause of the organization.

For example, the skills, knowledge, and personal traits Lovell and Kosten (2000) identify are individually focused. After all it is the individual student affairs professional who needs to understand student development theory. But one must go further than skill development for its own sake. A student affairs professional needs knowledge of student development theory (and many other things) in order to accomplish the organization's goals, so professional development must be, according to Winston and Creamer (1997), dually focused. Professional development must concern individual staff development in the pursuit of organizational development. There are models that facilitate the dual nature of professional development, notably Holmes (1998).

Holmes (1998) discusses professional development from the standpoint of human performance technology (HPT). To Holmes, HPT is the vehicle through which professional development should be accomplished. HPT involves linking organizational goals with an individual's ability to achieve those goals. Using a systematic process that identifies problems, causes of problems, and processes to remedy problems, the practitioner of HPT then seeks to manage change and assess the effectiveness of change. There are distinct benefits to using this type of system.

HPT facilitates skill development in the context of achieving organizational goals (Holmes, 1998). If, in the course of fostering individual skill development, organizational goals are not accounted for then professional development activities may serve only the betterment of the individual, thus losing the desired dual purpose. Woodard and Komives lamented a similar concern in 1990.

In discussing the current status of professional preparation Woodard and Komives (1990) noted the lack of qualified student affairs professionals that would be available to fill positions. Citing research on graduate preparation enrollment trends, Woodard and Komives stated that only half of those individuals employed in entry level student affairs positions have been properly trained. Professional development 
then becomes an extension of professional preparation programs and should be embarked on as a systematic process.

The means through which systematic professional development is accomplished are varied. Schwartz and Bryan (1998) discussed different categories of professional development activities: individual, group or program, departmental, divisional, and professional associations (p. 8). These are general classifications, and most professionals will recognize them. But there are other forms of professional development that are of benefit as well, one of them being mentoring.

Mentoring is a natural way of accomplishing professional development for the student affairs profession, given the field's helping profession background. Cooper and Miller (1998) viewed mentoring as a beneficial form of professional development. Their study also assessed the impact of mentoring and found that mentors provide career guidance, role modeling, and personal guidance to mentees. Nottingham (1998) called for the use of self-reflection in professional development. Self-refection, Nottingham argues, allows individuals to understand how they learn and what preferences they hold so they can more effectively improve themselves.

Perhaps the most comprehensive model for organization-based professional development in an appropriate context is synergistic supervision (Winston \& Creamer, 1997). Synergistic supervision is comprised of nine components, each relevant to professional development. First synergistic supervision serves a dual purpose, that of achieving the organizations goals and also attending to the "personal and professional welfare of the staff" (Winston \& Creamer, 1997, p. 197). Second, synergistic supervision involves both the supervisor and the staff member. Third, synergistic supervision uses two-way communication. Through two-way communication, staff and supervisor develop a trusting relationship. Fourth, synergistic supervision focuses on competence. Competence refers to the skills, knowledge, and traits necessary to perform a job function. Fifth, synergistic supervision concerns career growth and understanding of the career plans of staff. Sixth, synergistic supervision is proactive in identifying and addressing problems. Seventh, synergistic supervision is goal-focused and clear about expectations. Eighth, synergistic supervision uses systematic processes that are ongoing. This process allows for discussion 
of strengths and weaknesses in a consistent repetitive manner. Ninth, synergistic supervision is holistic, concerning both the staff member's professional and personal life (Winston \& Creamer, 1997).

In a later writing, Winston and Creamer (1998) further discussed synergistic supervision and professional development. They noted that, because of the dual purpose of professional development, professional development must be tied to the supervision process. Using the synergistic supervision process enables supervisors and supervisees to plan professional development activities that achieve the dual purposes of professional development. One of the most important aspects of this process of planning professional development is the open and trusting relationship critical to the synergistic supervision process.

The trusting relationship between the supervisor and staff member is critical in order to ensure that frank, open discussion about skill deficiency (or strength) occurs. Supervisory relationships that lack trust are not as likely to succeed as those that have developed trust. Once the relationship between supervisor and staff member is established then professional development activities that focus on individual and organizational needs, as well as activities that are consistent with the staff member's life and career goals, can take place (Winston \& Creamer, 1998).

\section{Discussion and Conclusion}

Professionalism is sometimes a hard sell as something to take seriously for many student affairs practitioners who would rather simply worry about serving students and doing their jobs. This may seem admirable, but it is shortsighted. If professionalism, scholarship, and professional development are crucial elements of student affairs practice as has been argued here, then four fundamental challenges to "business as usual" are obvious and need consideration:

\section{Intentionality of practice as a challenge to intuition, "natural ability," and experience}

Scholarly practice demands that professionals know what they are attempting to do with clients and groups of clients at all times. Further, they should be able to articulate theoretical and research- 
based reasons for their goals and actions. Doing what "seems" to be the "right thing" out of good intentions or out of a lack of other ideas is simply not good enough. Instinct, personality, and even successful experience are no substitute for appropriate professional education, reflection, and continual learning and professional development.

\section{Peer review of practice as a challenge to individual "initiative," isolation, and "privacy"}

Too much of our practice takes place in the "dark," out of the view of other professionals. We need to be willing and able to explain our actions and ask for opinions different from our own about issues facing students and student groups. Autonomy of action and practice are important, but always subject to review and change. We need to be more available to one another in nonjudgmental, but constructively critical ways. We need to make and seek peer judgments about office, divisional, and institutional goals and missions; about appropriate professional development activities; about necessary qualifications for positions; and a host of other issues, large and small. In addition, we need to make it clear that only student affairs professionals should be offering peer opinion, not those with other kinds of expertise, unless the question is a technical one relating to another specialty. In short, we claim that our field, at a minimum, is professional in practice; but we are not always taking the attendant responsibilities seriously.

\section{Consultation and community as a challenge to competition}

Educators don't compete, they collaborate. Professionals make themselves available to one another in networks as small as intra-office ones and as large as international. Although related to peer review, consultation is different; it is a kind of informed advice and support. Intentionality depends heavily upon consultation, since if one is unsure about what to do, he or she should do nothing until a good idea presents itself, often in the form of a conversation with a trusted colleague. Competition within institutions for resources or influence is cancerous and wrong. At a minimum, it takes energy and time away from students and at worst, it scuttles professionalism entirely. The same can be said about competition with other schools in some sort of nonsensical ratings rhetoric or a race to make almost proprietary strategies for retention and the promotion of success. The growth, learning, and success of all students is the primary goal of the student 
affairs profession. Professional, scholarly practice demands that we collaborate and consult. There is no place in our practice for pettiness, competition, or greed in whatever forms.

\section{Professional accountability as a challenge to "standards"}

Accountability should not reflect simplistic goals, written for management bureaucrats from outside the profession, using meaningless or even harmful "measurements" or "ratings" that result in increased injustice and inequity on campuses or in a false kind of success based on profit or efficiency. Rather, professional accountability is meaningful to students, peers, and the profession of student affairs work, in the context of the institution in which one practices (Carpenter, 20003). This is not to eschew excellent management, but instead to demand it in the sense that efficiency is empty without effectiveness. Assessment should be not only ubiquitous, but also meaningful, or else as a profession "we rely on superstition, whimsy, tradition, or inertia" (Carpenter, 2001, p. 314).

These challenges demonstrate that the way forward for excellent service to students lies in professionalism, scholarship, and continual professional learning and development. Clearly, this requires a commitment, perhaps even a calling, to help students; and to be an active part of a professional community, being accountable to oneself more stringently and to a broader group of professionals than usually envisioned.

The challenges of professionalism and scholarly practice show that simple activity and hard work are not enough, nor even close. Only continuous reflection, commitment, learning, and growth are acceptable if we are to be of service to our students and our institutions. We owe our profession nothing less.

\section{References}

American College Personnel Association. (2006). Statement of ethical principles and standards. Retrieved December 18, 2006, from http://www.myacpa.org/au/documents/ EthicsStatement.pdf Allen, K. E. (2002). The purpose of scholarship: Redefining meaning for student affairs. NASPA Journal, 39, 147-157. 
American Council on Higher Education. (1937). 1937 student personnel point of view. Washington, DC: NASPA.

Blimling, G. S. (2001). Uniting scholarship and communities of practice in student affairs. Journal of College Student Development, 42, 381-396.

Brint, S. (1993). Eliot Friedson's contribution to the sociology of professions. Work \& Occupations, 20(3), 259-279.

Carpenter, D. S. (1991). Student affairs profession: A developmental perspective. In T. K. Miller, R. B. Winston, Jr. and Associates (Eds.), Administration and leadership in student affairs (pp. 253-278). Muncie, IN: Accelerated Development.

Carpenter, D. S. (2001). Student affairs scholarship (re?)considered: Toward a scholarship of practice. Journal of College Student Development, 42, 301-318.

Carpenter, D. S. (2003). Professionalism in student affairs work. In S. Komives \& D. Woodard (Eds.) Student Services: A Handbook for the Profession (4th ed., pp. 573-591). San Francisco: Jossey-Bass.

Carpenter, D. S., Miller, T. K., \& Winston, R. B., Jr. (1980) Toward the professionalization of student affairs. NASPA Journal, 18(2), $16-22$.

Cervero, R. M. (2000). Trends and issues in continuing professional education. In. V. W. Mott \& B. J. Daley (Eds.), Charting a course for continuing professional education: Reframing professional practice (pp. 3-12). New Directions for Adult and Continuing Education, No. 86. San Francisco: Jossey-Bass.

Cooper, D. L., \& Miller, T. K. (1998). Influence and impact: Professional development in student affairs. In W. A. Bryan \& R. A. Schwartz (Eds.), Strategies for staff development: Personal and professional education in the 21st century (pp. 55-69). New Directions for Student Services, No. 84. San Francisco: JosseyBass.

Council for the Advancement of Standards in Higher Education. (2003). Standards and guidelines for student services development programs. Washington, DC: American College Personnel Association. Davis, T., \& Liddell, D. (1997). Publication trends in the Journal of College Student Development: 1987-1995. Journal of College Student Development, (38), 325-332.

Dirkx, J. M., Gilley, J. W., \& Gilley, A. M. (2004). Change theory in CPE and HRD: Toward a holistic view of learning and change in work. Advances in Developing Human Resources, 6, 35-51. 
Evans, N. J., \& Reason, R. D. (2001). Guiding principles: A review and analysis of student affairs philosophical statements. Journal of College Student Development, 42, 359-377.

Fried, J. (2002). The scholarship of student affairs: Integration and application. NASPA Journal, 39(2), 120-131.

Friedson, E. (1986) Professional Powers. Chicago: University of Chicago Press.

Hirt, J. B., \& Creamer, D. G. (1998). Issues facing student affairs professionals: The four realms of professional life. In N. J. Evans \& C. E. P. Tobin, The state of the art of preparation and practice in student affairs: Another look. Lanham, MD: University Press of America.

Holmes, T. A. (1998). Performance-based approaches to human resource development. In W. A. Bryan \& R. A. Schwartz (Eds.), Strategies for staff development: Personal and professional education in the 21st century (pp. 14-28). New Directions for Student Services, No. 84. San Francisco: Jossey-Bass.

Janosik, S., Carpenter, S., \& Creamer, D. (2006). Beyond professional preparation: programs: The role of professional associations in ensuring a high quality work force. College Student Affairs Journal, 25(2), 228-237.

Knox, A. B. (2000). The continuum of professional education and practice. In. V. W. Mott \& B. J. Daley (Eds.), Charting a course for continuing professional education: Reframing professional practice (pp. 13-22). New Directions for Adult and Continuing Education, No. 86. San Francisco: Jossey-Bass.

Knox, A. B. (1993). Strengthening adult and continuing education: A global perspective on synergistic leadership. San Francisco: Jossey-Bass.

Lovell, C. D., \& Kosten, L. A. (2000). Skills, knowledge, and personal traits necessary for success as a student affairs administrator: A meta-analysis of thirty years of research. NASPA Journal, 37, 553-572.

Malaney, G. D. (2002). Scholarship in student affairs through teaching and research. NASPA Journal, 39, 132-146.

NASPA. (2006). NASPA salary survey. Retrieved December 19, 2006, from http://www.naspa.org/membership/mem/salary_info.cfm?er=1

Nottingham, J. E. (1998) Using self-reflection for personal and professional development in student affairs. In W. A. Bryan \& R. A. Schwartz (Eds.), Strategies for staff development: Personal and professional education in the 21st century (pp. 71-81). New Directions for Student Services, No. 84. San Francisco: Jossey-Bass. 
Pavalko, R. M.(1971). Sociology of occupations and professions. Itasca, IL: F.E. Peacock.

Saunders, S., Register, M., Cooper, D., Bates, J., \& Dadonna, M. (2000). Who is writing research articles in student affairs journals/practitioner involvement and collaboration? Journal of College Student Development, (41), 609-615.

Schroeder, C. C., \& Pike, G. R. (2001). The scholarship of application in student affairs. Journal of College Student Development, 42, 342-355.

Schwartz, R. A., \& Bryan, W. A. (1998). What is professional development? In W. A. Bryan \& R. A. Schwartz (Eds.), Strategies for staff development: Personal and professional education in the $21^{\text {st }}$ century (pp. 3-13). New Directions for Student Services, No. 84. San Francisco: Jossey-Bass.

Stamatakos, L. C. (1981). Student affairs progress toward professionalism: Recommendations for actions (Pt 1 and 2). Journal of College Student Personnel, 22, 105-111, 197-206.

Veysey, L. R. (1988). Marxism and class theory: A bourgeois critique. New York: Columbia University Press.

Wilensky, H. L. (1964). The professionalization of everyone? American Journal of Sociology, 70, 137-158.

Winston, R. B., Jr., Creamer, D. G., \& Miller, T. K. (2001). The professional student affairs administrator: Educator, leader, and manager. New York: Brunner-Routledge.

Winston, R. B., Jr., \& Creamer, D. G. (1998). Staff supervision and professional development: An integrated approach. In W. A. Bryan $\&$ R. A. Schwartz (Eds.), Strategies for staff development: Personal and professional education in the 21st century (pp. 29-42). New Directions for Student Services, No. 84. San Francisco: JosseyBass.

Winston, R. B., Jr., \& Creamer, D. G. (1997). Improving staffing practices in student affairs. San Francisco: Jossey-Bass.

Woodard, D. B., Jr., \& Komives, S. R. (1990). Ensuring staff competence. In M. J. Barr \& M. L. Upcraft (Eds.), New futures for student affairs (pp. 217-238). San Francisco: Jossey-Bass.

Young, R. B. (2001). A perspective on the values of student affairs and scholarship. Journal of College Student Development, 42, 319-337. 